\author{
Military Technical College \\ Kobry El-Kobbah \\ Cairo, Egypt
}

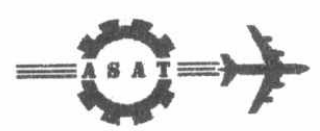

$10^{\text {th }}$ International Conference

On Aerospace Sciences\&

Aviation Technology

\title{
EVALUATION OF FILTERING ELEMENTS AND ITS EFFECT ON AIR FILTER PERFORMANCE CHARACTERISTICS
}

\author{
REDA HASSAN KHODARY * and MABROUK MOHAMED IBRAHIM **
}

\section{ABSTRACT}

The air filtering element in any internal combustion engine greatly influences the performance and service life of the engine. The pressure drop across the air filter affects the engine power. Furthermore, the fine dust carried by the air permeated through the filtering element remarkably affects the development of wear in cylinder liners and piston rings. Therefore, a great care should be given to the selection of filtering element in the process of engine design.

This paper presents a set of experiments conducted in order to investigate the characteristics of six different types of commercial filtering elements used in the production of local air filters. Two paper, two synthetic, and two wire types of filtering elements were selected for this purpose. They were tested for the resistance characteristics at different values of air flow rate in natural room conditions. For measuring the efficiency and capacity characteristics of filtering elements, tests were conducted at constant air flow. In general the paper type was found to have higher pressure drop and higher efficiency but with lower capacity to retain dust compared to synthetic and wire materials. Analysis of the results in addition to conclusions are included.

\section{NOTATION:}

$d_{p}$ : Diameter of dust particle $(\mu \mathrm{m})$.

$d_{f}$ : Diameter of the fiber $(\mu \mathrm{m})$.

g: gravity acceleration

$\mathrm{R}:$ Resistance of air filter $(R=\Delta P)$

$\mathrm{P}_{\mathrm{a}}:$ Atmospheric pressure

$Q_{T}$ : Total quantity of dust that enters to air filter $\left(\mathrm{m}^{3} / \mathrm{hr}\right)$

$Q_{A C}:$ Quantity of dust that caught in air filter $\left(\mathrm{m}^{3} / \mathrm{hr}\right)$

$Q_{e n}$ : Quantity of dust, which enters to the engine $\left(\mathrm{m}^{3} / \mathrm{hr}\right)$

\footnotetext{
• Col. Dr. Eng., Chief of Tanks Department, M.T.C, Cairo, Egypt.

** Lit. Col. Eng., Graduate student, Dpt. Of Tanks, M.T.C, Cairo, Egypt.
} 
$Q_{0}:$ Hamaker's constant of interaction

$\Delta W_{f}$ : Increase in mass of tested filter

$\Delta W_{a}:$ Increase in mass of absolute filter

$T_{i}:$ Total time to end of the $\mathrm{i}^{\text {th }}$ interval

$T$ : Total time to end of test

$U:$ Flow velocity

$\mu$ : Dynamic viscosity of fluid

$\rho_{p}:$ Density of particle

\section{INTRODUCTION}

The air filter, which is an important aggregate of the vehicle engine, is charged with removing dust from the air drawn into the engine. If dust is allowed to enter the engine cylinder, it will act as an abrasive compound and shorten the service life of bearing surfaces, particularly those of cylinder liners and piston rings. Air filtration is the process of dust separation by passing the dust-air mixture through a filtering medium that retains dust and lets air pass. Thus the successful operation of an air filter largely depends upon the performance of the filtering medium and its capability to separate suspended solids.

Dust is separated by the porous medium under the action of several mechanisms. The intensity of each mechanism is described by a dimensionless quantity called the characteristic parameter. The rate of settlement (separation) of dust particles by each mechanism is given by its capture coefficient, which is a function of the characteristic parameter. The filter efficiency is thus a collective function of the capture coefficients of the separate mechanisms acting simultaneously. Different investigations of the function of the capture coefficients and efficiency gave several formulae $(1,3,4,7)$.

The important mechanisms in case of fibrous media are as follows:

1- Direct interception: When the trajectory of the center of a dust particle approaches the fiber of porous medium at a distance less or equal to the particle radius, the particle is intercepted on the fiber surface. The characteristic parameter $N_{R}$ of this mechanism is given by:

$$
N_{R}=\frac{d_{p}}{d_{f}}
$$

A special case of this mechanism is the sieve action, where the particle is intercepted if the pore size (or the distance between fibers) is smaller than the particle diameter.

2- Inertial Settlement: The dust particles due to their inertia are deviated from the curved streamlines and projected against the fiber surface (their trajectory reaches the fiber). For Stokes particles (spherical particles obeying Stokes low), the characteristic parameter is the Stokes number $S_{d k}$ :

$$
S_{t k}=\frac{\rho_{p} d_{p}^{2} U}{18 \mu d_{f}}
$$


3- Gravitational Settlement: A dust particle in an air flow of a certain velocity has a settling velocity due to gravity (Stokes relation). This leads to deviation of particle trajectory from the fluid streamlines. Owing to such deviation the particle may touch and settle on the medium fibers. The intensity of this process increases for the large particles and for smaller flow velocity. Ratio of settling velocity $V_{s}$ to the flow velocity $U$ defines the characteristic parameter, $N_{G}$, of this mechanism, given as:

$$
N_{G}=\frac{V_{s}}{U}=\frac{\rho_{p} d_{p}^{2} g}{18 \mu U}
$$

4- Diffusion Settlement: When the disperse system flows close to the fibers of porous medium the trajectories of submicron particles are deviated from the fluid streamlines due to the Brownian motion and may settle on the fiber surfaces. The intensity of this process increases with the decrease of the size of particles and the velocity of flow and the increases of the specific surface of filtering medium. The characteristic parameter, $N_{D}$, of this mechanism is the reciprocal value of Peclet number, $P_{e}$

$$
N_{D}=P_{e}^{-1}=\frac{D}{d_{f} U}
$$

The mass fraction $X_{D}$ of flowing particles of certain size, $d_{p}$ which may settle by diffusion, can be determined by simple formula.

$$
X_{D}=\frac{1.35 * 10^{-2}}{\mu \cup d_{p} d_{f}}
$$

5- Settlement due to Van der Waals forces: When the distance between a particle and a fiber is very small, the particle may settle under the influence of molecular interaction (Van der Waals forces) between the particle and fiber. The characteristic parameter $N_{M}$ of this mechanism is given by:

$$
N_{M}=\frac{Q_{0} r_{p}^{2}}{9 \pi \mu U r_{f}^{4}}
$$

6- Electrostatic Settlement: One or both of the dust particle and fiber may carry electrostatic charges and consequently the particle may settle on the fiber due to the forces of interaction between charges. Ratio of the interaction force to the viscous medium resistance is the characteristic parameter of this mechanism, $N_{E S}$. When a particle carries a charge $q$ and the fiber carries a charge $Q$ per unit length, $N_{E S}$ is defined as:

$$
N_{E S}=\frac{4 Q q}{3 \pi \mu d_{p} d_{f} U}
$$

Referring to the nature of the different mechanisms, two basic filtration techniques are distinguished:

- Surface filtration

- Volume filtration

In the surface filtration, the dust particles are separated on the surface of porous medium mainly due to direct interception. In this technique, the settlement and 
accumulation of the initial dust particles on the surface of filtering medium results in the formation of a dust cake, whose porosity is smaller than that of the original filter (porous medium). The cake formation improves the fiiter efficiency but a higher pressure loss develops. Surface filtration is typical for thin filtering media like paper.

In volume filtration, the dust particles are separated within the whole volume of filtering medium whereas the different mechanisms act simultaneously with adequate probabilities. This is typical for thick filtering media like the cartridges of metallic wire, graded fibers and polymers. Inertia filters. The theory of operation of such filters is based on the inertia difference between the particulate phase and that of the suspended medium. Air can easily change its direction, whereas sand particles (having much higher inertia) will fail to follow the change in the stream direction. These particles will settle down and leave or separate from the mixture, hence reducing the concentration of sand in the air. Such action may be achieved by centrifugal force. Inertia filters could be either dry or the wet.

Porous medium is a solid containing voids either interconnected or non-connected. If the voids are interconnected throughout the medium thickness, they form open pores, otherwise closed pores are formed. Fibrous, vacuole and granulated porous media are widely used for filtration. Its porosity, specific surface, permeability, size, dimensions, chemical composition and electrostatic properties characterize the porous medium.

The filtering media used in air filters of internal combustion engines may be papers, felts, fabrics, glass fiber, and mineral wool.

\section{TESTING OF AIR FILTER}

The aim of the testing is to determine experimentally the basic performance characteristics of air filter (6):

1. Resistance Characteristics: Evaluation of the pressure drop $\left(\Delta^{P}\right)$ and its dependence on discharge $Q$ (flow rate through filter) with the filter cleaned. The pressure drop results in decreasing the engine power. This decrease $\Delta N$ is calculated according to the formula:

$$
\Delta N=\frac{R}{P_{a}} 100 \quad(\%)
$$

2. Efficiency Characteristics: Variation of filter efficiency $\eta_{A C}$ with the weight of retained dust by filter at a fixed discharge. The efficiency of air filter is defined as:

$$
\eta_{A . C}=\frac{Q_{A . C}}{Q_{T}} 100=\frac{Q_{T}-Q_{e n}}{Q_{T}} 100
$$

3. Holding Capacity Characteristics: Variation of filter resistance (pressure drop across the filter) with the weight of retained dust by filter. The air filter must have high holding capacity, which is a requirement for long time operation with high efficiency. 


\section{EXPERIMENTAL WORK}

Experiments were conducted on different available types of filtering media to determine their basic performance characteristics. Laboratory facilities available at the Military Technical College and controlling Exports \& Imports authority have been used throughout this work. The filtering media tested are those which are being locally used in manufacturing air filters of vehicles. They incorporate six types of filtering media of the same face area operating on different principles (surface and volume), namely:

- Two types of paper filter media

- Two types of synthetic filter media

- Two types of wire filter media

The most commonly used paper media is the cellulose acetate paper. These paper media can also have synthetic fibers blended with cellulose fibers to add strength. The cellulose paper media also use a variety of resin systems to improve performance and processing actions. Cellulose paper media are also impregnated with oil and other treatments to significantly improve their performance level especially at higher face velocities.

The basic characteristics of the two types of the tested paper filtering media are listed in the table 1.

Table 1. Technical data of paper filtering media.

\begin{tabular}{|l|l|l|}
\hline Type & Paper 1 & Paper 2 \\
\hline Mean fiber diameter, $\mathrm{d}_{\mathrm{f}}(\mu \mathrm{m})$ & 6.5 & 15 \\
\hline Average efficiency (SAF) \% & 99 & 98 \\
\hline
\end{tabular}

The synthetic materials are produced from synthetic fibers in the form of sheets. The synthetic felt media provides excellent durability, heat resistance, water resistance, structural integrity, filtration performance etc. The felt media due to its thickness rely on depth filtration to capture and remove the particles. By paper formulation of fiber size and fiber size distributions, the synthetic felts can also be designed to deliver higher efficiency. Two types of synthetic media were testing:

- R50 super medium, distinguished here as synthetic 1

- R 15 economy medium, distinguished here as synthetic 2

The tested specimens are prepared from layers of the media of total thickness 30 $\mathrm{mm}$ for the two types. The technical data of the two types of synthetic media are listed in table 2.

Table 2. Technical data of synthetic filtering media

\begin{tabular}{|l|c|c|}
\hline \multicolumn{1}{|c|}{ Type } & Synthtic1 & Synthetic 2 \\
\hline Medium color & White & White \\
\hline Number of layers & 3 & 6 \\
\hline Total thickness $(\mathrm{mm})$ & 30 & 30 \\
\hline Maximum operating temperature $\left({ }^{\circ} \mathrm{C}\right)$ & 100 & 100 \\
\hline Washability & Good & Limited \\
\hline Recommended face velocity $(\mathrm{m} / \mathrm{s})$ & 1.5 & 1.5 \\
\hline Rated initial resistance $(\mathrm{Pa})$ & 42 & 17 \\
\hline Recommended final resistance $(\mathrm{Pa})$ & 200 & 130 \\
\hline
\end{tabular}


The wire materials are produced from wire fibers in the form of sheet. There are two types of wire media specimens designated as:

- Wire medium 1 (high density)

- Wire medium 2 (low density)

The technical data of the two types of wire media are given in table 3 :

Table 3. Technical data of wire filtering media.

\begin{tabular}{|l|l|l|}
\hline Type & High density & Low density \\
\hline Surface area $\left(\mathrm{cm}^{2}\right)$ & 615 & 615 \\
\hline Mass $(\mathrm{gm})$ & 1405 & 538 \\
\hline Volume $\left(\mathrm{cm}^{3}\right)$ & 1845 & 1845 \\
\hline Density $\left(\mathrm{gm} / \mathrm{cm}^{3}\right)$ & 0.946 & 0.292 \\
\hline Diameter of wire $(\mathrm{mm})$ & 0.23 & 0.23 \\
\hline
\end{tabular}

The test dust used for measuring the performance characteristics of the chosen filtering media was obtained from controlling Exports \& Imports authority is the SAE standard dust of coarse grade with chemical composition and the particle size distribution as listed in table 4 and 5 .

Table 4. Chemical analysis of test dust.

\begin{tabular}{|l|l|}
\hline Chemical Composition & $\begin{array}{l}\text { Percentage by weight } \\
\%\end{array}$ \\
\hline $\mathrm{SiO}_{2}$ & 67 to 69 \\
\hline $\mathrm{Fe}_{2} \mathrm{O}_{3}$ & 3 to 5 \\
\hline $\mathrm{Al}_{2} \mathrm{O}_{3}$ & 15 to 17 \\
\hline $\mathrm{CaO}$ & 2 to 4 \\
\hline $\mathrm{MgO}$ & 0.5 to 1.5 \\
\hline Total alkalis & 3 to 5 \\
\hline
\end{tabular}

Table 5. Particle size distribution of test dust.

\begin{tabular}{|l|c|}
\hline Size $(\mu \mathrm{m})$ & Percentage by weight \\
\hline 0 to 5 & $12 \pm 2$ \\
\hline 5 to 10 & $12 \pm 3$ \\
\hline 10 to 20 & $14 \pm 3$ \\
\hline 20 to 40 & $23 \pm 3$ \\
\hline 40 to 80 & $30 \pm 3$ \\
\hline 80 to 200 & $9 \pm 3$ \\
\hline
\end{tabular}

\section{TESTING PROCEDURE AND CONDITIONS}

For measuring the resistance characteristics, the test rig shown in figures 1 and 2 was used. Air is sucked through the piping across the test sample fixed in holder (1) by means of the centrifugal fan (10) driven by the electric motor (7). The air flow rate is controlled by the shutter (9). The air flow rate is measured by means of the orificemeter consisting of the orifice plate (6) and the differential manometer (5). The pressure drop across the test sample and subsequent piping is measured by ordinary manometer (2). Before mounting the test sample, the pressure drop across piping $\Delta \mathrm{P}_{\rho}$ was determined at different values of air flow rate of $150,200,250,300,350$, 
$400,450,500$, and $550 \mathrm{~m}^{3} / \mathrm{hr}$ by means of ordinary manometer (2). The clean test sample was mounted and the total pressure drop across the filter and the piping $\left(\Delta P_{t}\right)$ was measured at the same values of air flow rate. Hence, the pressure drop across the test sample $\Delta P$ was determined as follows:

$$
\Delta P=\Delta P_{t}-\Delta P_{p} \quad \text { for each } Q
$$

For measuring the efficiency and capacity characteristics, the test rig shown in figures 3 and 4 was used. The tested medium is mounted and dust is supplied by the dust feeder (1). The weights of tested filter (cleaned) $W_{f 1}$ and absolute filter $W_{a 1}$ were determined before mounting into the system. The air flow rate was adjusted to the value of $400 \mathrm{~m}^{3} / \mathrm{hr}$ using the control shutter and orificemeter. Dust was injected into the chamber (2) at a rate corresponding to the required dust concentration in the air sucked into filter $(0.222 \mathrm{gm} / \mathrm{s})$. After each specific time interval $(5 \mathrm{hr})$, weights of filters $W_{f 2}$ and $W_{a 2}$ were determined and the pressure drop $\Delta P$ across the filter was recorded. The efficiency $\eta$ was calculated as follows:

$$
\eta=\frac{\Delta W_{f}}{\Delta W_{f}+\Delta W_{a}} 100
$$

where, $\left(\Delta W_{f}=W_{f 2}-W_{f 1}\right)$ and $\left(\Delta W_{a}=W_{a 2}-W_{a 1}\right)$

The efficiency characteristics are obtained by tracing the function

$$
\eta=f\left(W_{f}\right) \quad \text { at constant discharge } Q
$$

The increase of tested filter weight $\Delta W_{f i}$ at certain time interval of 60 minute through a time span $\mathrm{T}:$ :

$$
\Delta W_{f i}=\frac{T_{i}}{T} \Delta W_{f}
$$

The capacity characteristics are obtained by tracing the function

$$
\Delta P=f\left(\Delta W_{f i}\right)
$$

During this test, the discharge $Q$ was kept at the prescribed value (by the control shutter), since it tends to decrease due to continuous contamination of filters.

Testing of filtering media was developed at the following conditions:

- Concentration of dust: $2\left(\mathrm{gm} / \mathrm{m}^{3}\right)$

- Temperature: $23 \pm 5^{\circ} \mathrm{C}$

- Relative humidity: $55 \pm 15 \%$

\section{RESULTS AND DISCUSSION}

\section{Resistance characteristics}

Figure 5 shows the relation between the resistance $\Delta P$ and air flow rate (Q) for paper 1 , paper 2 , synthetic 1 , synthetic 2 , wire 1 , and wire 2 . The figure shows an increase of pressure drop for all filtering elements as a function of air discharge. The rate of augmentation of pressure drop is highest in case of paper filter (operation on the principle of surface filtration) due to the smallest pore size in comparison with synthetic and wire filters (operating on the principle of volume filtration). 


\section{Efficiency characteristics}

The results of the weight of dust retained by the chosen filtering media and absolute filter and the value of efficiency calculated by equation (10) are given in table 6 . For all types of tested media, the efficiency was measured after 5 hours operation.

Table 6. Experimental results for efficiency calculation of tested filtering media.

\begin{tabular}{|c|c|c|c|c|c|c|c|}
\hline Medium & $\begin{array}{c}\text { Time } \\
(\mathrm{hrs})\end{array}$ & $\begin{array}{c}W_{f} \\
(\mathrm{gm})\end{array}$ & $\begin{array}{c}W_{a} \\
(\mathrm{gm})\end{array}$ & $\begin{array}{c}\Delta W_{f} \\
(\mathrm{gm})\end{array}$ & $\begin{array}{c}\Delta W_{a} \\
(\mathrm{gm})\end{array}$ & $\begin{array}{c}\Delta W_{f}+\Delta W_{a} \\
(\mathrm{gm})\end{array}$ & $\begin{array}{c}\eta \\
(\%)\end{array}$ \\
\hline \multirow{2}{*}{ Paper 1 } & 0 & 3322 & 15742 & 0 & 0 & 0 & Max. \\
\cline { 2 - 8 } & 5 & 3387 & 15744 & 65 & 2 & 67 & 97.015 \\
\hline Paper 2 & 0 & 3325 & 15489 & 0 & 0 & 0 & Max. \\
\cline { 2 - 8 } & 5 & 3767 & 15492 & 42 & 3 & 45 & 93.333 \\
\hline \multirow{2}{*}{ Synthetic1 } & 0 & 3336 & 15480 & 0 & 0 & 0 & Max. \\
\cline { 2 - 8 } & 5 & 3406 & 15493 & 70 & 13 & 83 & 84.3 \\
\hline Synthetic2 & 0 & 3332 & 15723 & 0 & 0 & 0 & Max. \\
\cline { 2 - 8 } & 5 & 3399 & 15740 & 67 & 17 & 84 & 79.76 \\
\hline \multirow{2}{*}{ Wire 1 } & 0 & 3890 & 16046 & 0 & 0 & 0 & Max. \\
\cline { 2 - 8 } & 5 & 3965 & 16065 & 75 & 21 & 96 & 78.1 \\
\hline Wire 2 & 0 & 3817 & 15662 & 0 & 0 & 0 & Max. \\
\cline { 2 - 8 } & 5 & 3889 & 15688 & 72 & 26 & 98 & 73.469 \\
\hline
\end{tabular}

Table 6 shows that highest efficiency was observed with paper filters. That is due to smaller porosity and cake formation in paper filter (surface filtration). The synthetic medium comes next to paper then wire media.

\section{Capacity Characteristics}

Figure 6 shows the relation between the pressure drop and the retained dust for the different tested filtering media. The figure indicates an increase of pressure drop with contamination of filters (increase of quantity of retained dust) but with higher rate in case of paper filter, which means that, it gets clogged quickly. As a result, the capacity of paper filter is found to be smaller which limits the service duration of paper filters.

\section{CONCLUSIONS}

1. The performance characteristics of three types of filtering media used in automotive air filters have been measured experimentally. The tested units are paper, synthetic, and wire media. Two kinds of each medium were used. Testing aimed of evaluating the resistance, efficiency, and capacity characteristics of each tested media.

2. The pressure drop across the filter medium was found to increase with air flow rate for all types of media. This is referred to the increase of friction losses with flow velocity resulting from higher flow rates.

3. The results indicate that the paper media (operating on the principle of surface filtration) have the highest pressure drop and highest efficiency but with lower capacity to retain dust comparative other two types. Therefore, 
paper filters should be limited to the conditions of low dust concentration due to quick clogging.

4.

For the conditions of medium and heavy dust concentration, filters operating on the principle of volume filtration could be used due their grater capacity.

\section{REFERENCES}

[1] Mabrouk, M. I. "Vehicle Filter Evaluation and its Effect on Equipment Service Life.", M.Sc. Thesis, M.T.C., Cairo, (2001).

[2] SAE "Air Cleaner Test Code.", (1987).

[3] Zidan, A. M. "Analysis of Basic Problems of Air filtration" $2^{\text {nd }}$ A.S.A.T conference, M.T.C, Cairo, Egypt, (1987).

[4] Liu, B. Y. H. et Rubow, K. L. "Air Filtration by Fibrous Media.", University of Minnesota, USA, (1986).

[5] Read, B. "Air Filtration in Reciprocating Machines.", Loker Air Maze, Hydraulic Pneumatic Mechanical Power, (1984).

ISO "Instruction For Air Cleaner Testing" (1973).

[6]

Gordon, G. et Peisakhav, L. "Dust Collection and Gas Cleaning.", Mir Publishers, Moscow, (1972). 


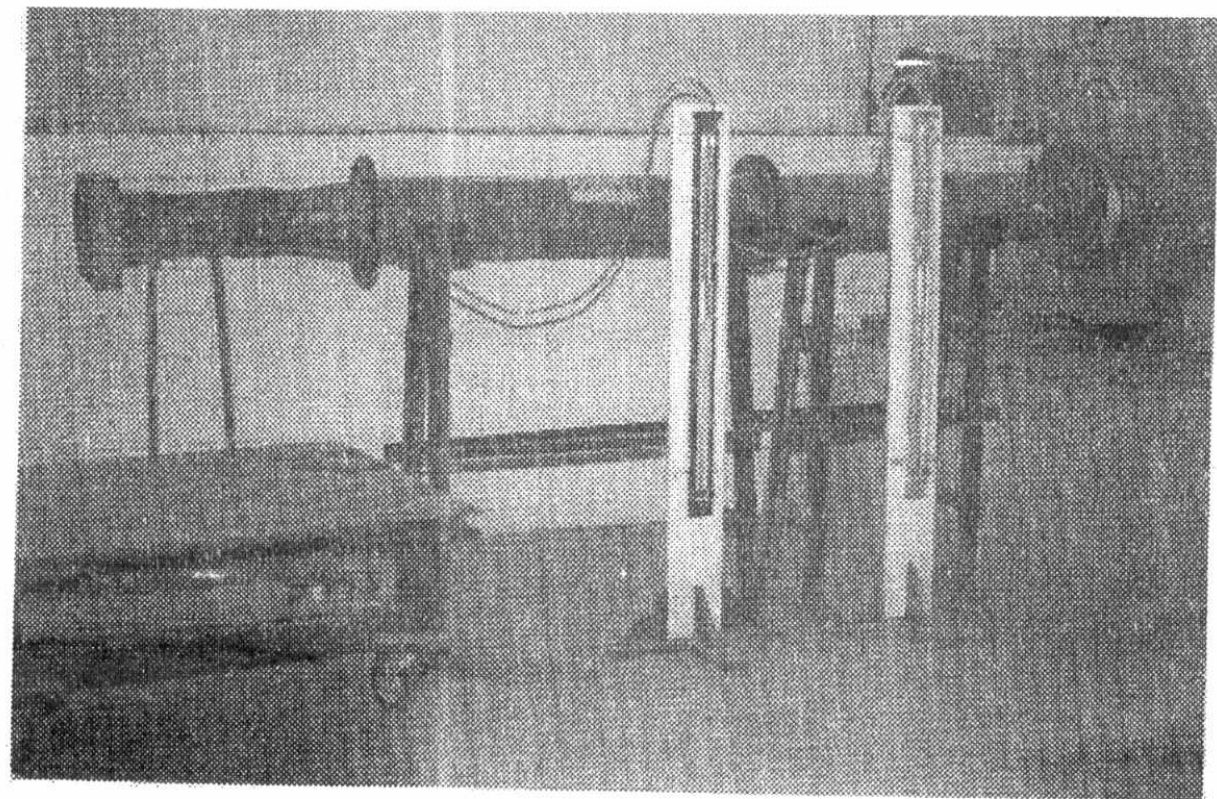

Fig.1. Test rig used for measuring resistance characteristics.

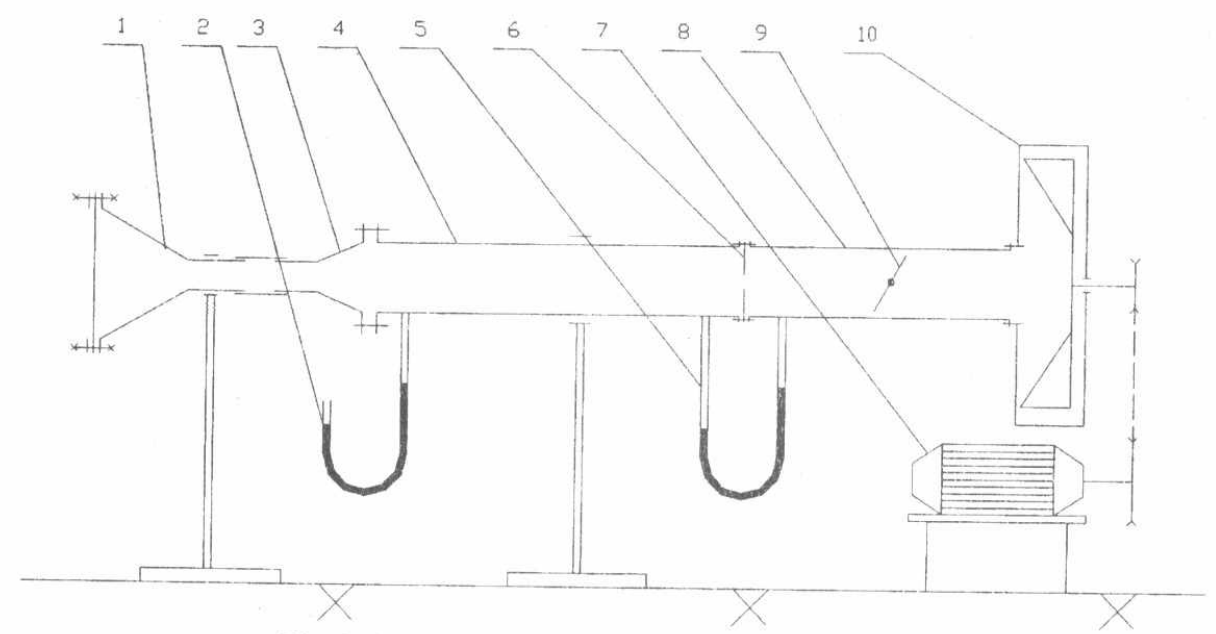

Fig.2. Schematic diagram of test rig assembly, used for measuring resistance characteristics

1- Holder of tested sample 2-Manometer 3-Connecting cone 4- Front pipe 5-Differential manometer 6-Orifice plate 7-Electric motor 8- Rear pipe 9-Control shutter 10-Centrifugal fan 


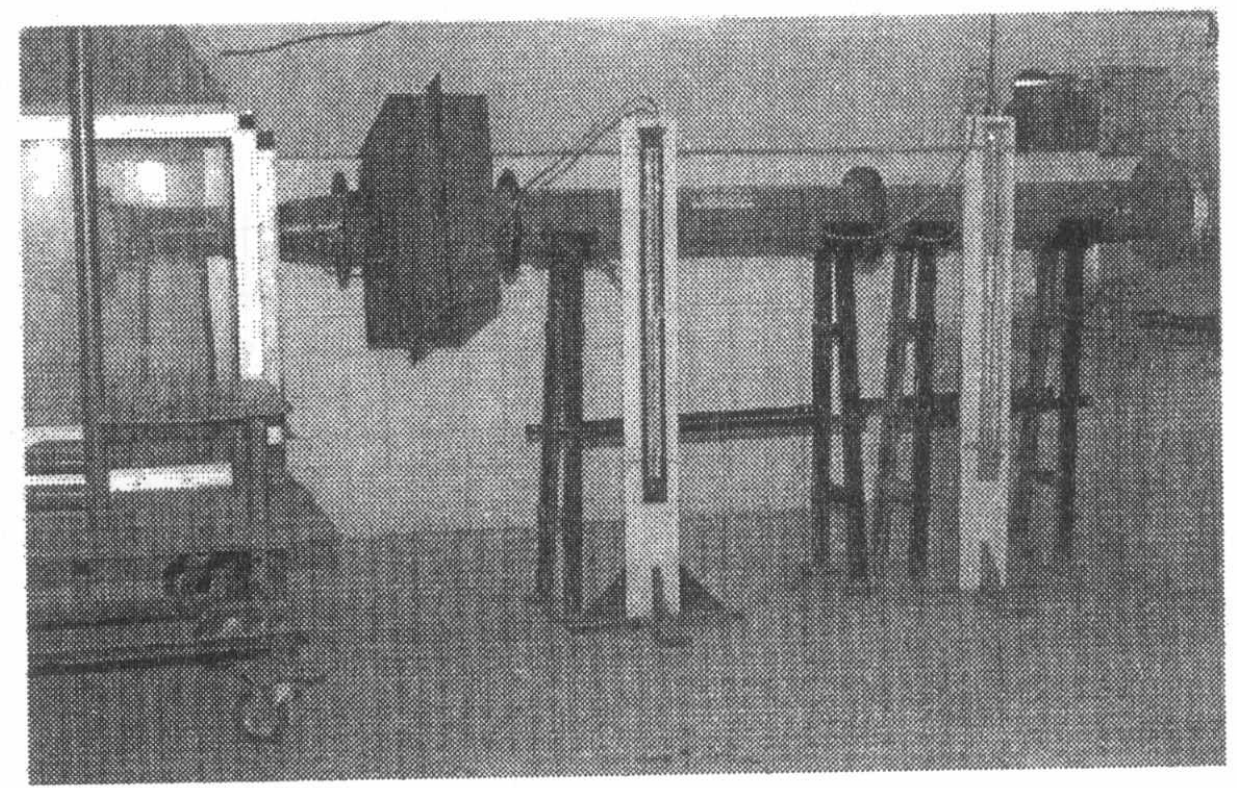

Fig.3. Test rig used for measuring efficiency and capacity characteristics.

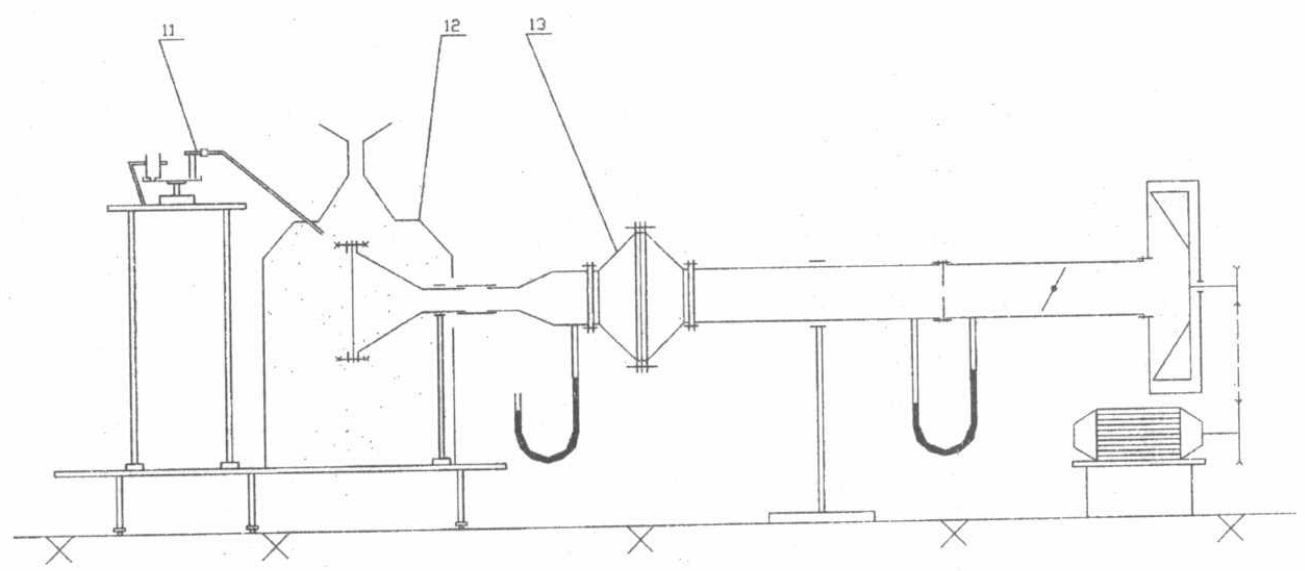

Fig.4. Schematic diagram of test rig assembly, used for measuring efficiency and capacity characteristics
1- Dust feeder
2- Dust chamber
3- Absolute filter 


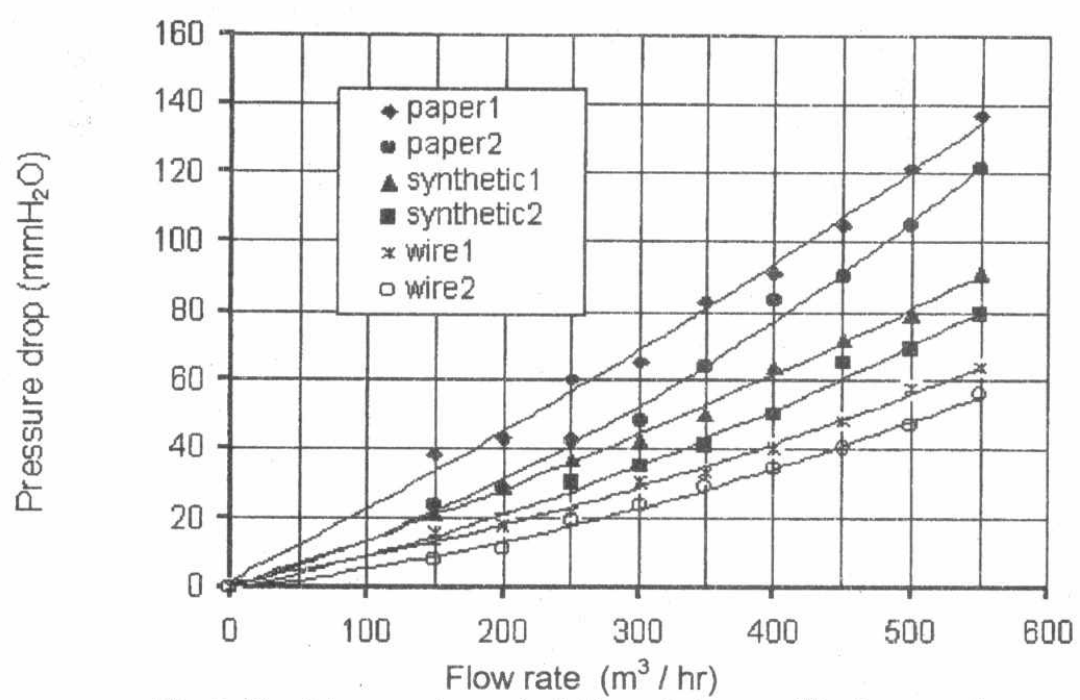

Fig.5. Resistance characteristics of chosen filtering media.

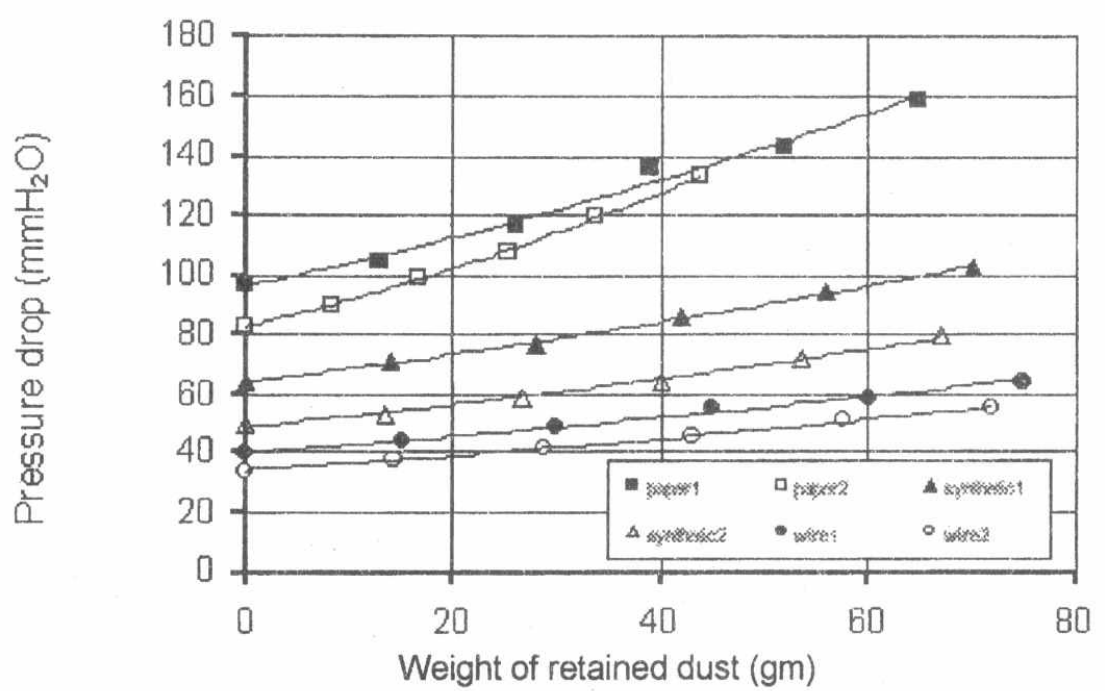

Fig.6. Capacity characteristics of chosen filtering media. 